\title{
Painting
}

\section{Soar: A Glimpse of Hope During the Pandemic}

Nafisa Choudhury

\section{Abstract}

Author affiliations are listed at the end of this article.

\section{Description}

This original watercolor and ink painting features a cardinal with its wings spread against a blue sky. The cardinal symbolizes pivotal moments, and we as a nation find ourselves at a pivotal moment with regards to our handling of the coronavirus pandemic. The bird with its wings spread against the sky gives a vision of anticipation. These feelings of hope and anticipation mimic those that many are starting to feel as vaccine distribution has ramped up. Health workers should take a moment to acknowledge this extraordinary state that we have reached while continuing our care and following CDC guidelines. We hope that we will soar into a new tomorrow where we are able to tackle the pandemic and we appreciate that we are allowed a glimpse of hope into a return to normal.

\section{Keywords}

medicine in the arts; pandemics; SARS-CoV-2; COVID-19; COVID-19 vaccines; painting; hope

\section{Conflicts of Interest}

The author declares she has no conflicts of interest.

\section{Author Affiliation}

1. Dr. Kiran C. Patel College of Allopathic Medicine, Nova Southeastern University, Fort Lauderdale, FL
Correspondence to: Nafisa Choudhury

Dr. Kiran C. Patel College of Allopathic Medicine Nova Southeastern

University

Fort Lauderdale, FL 33328

(nc1083@mynsu.nova.edu) Emerald Medical Education 
HCA Healthcare Journal of Medicine

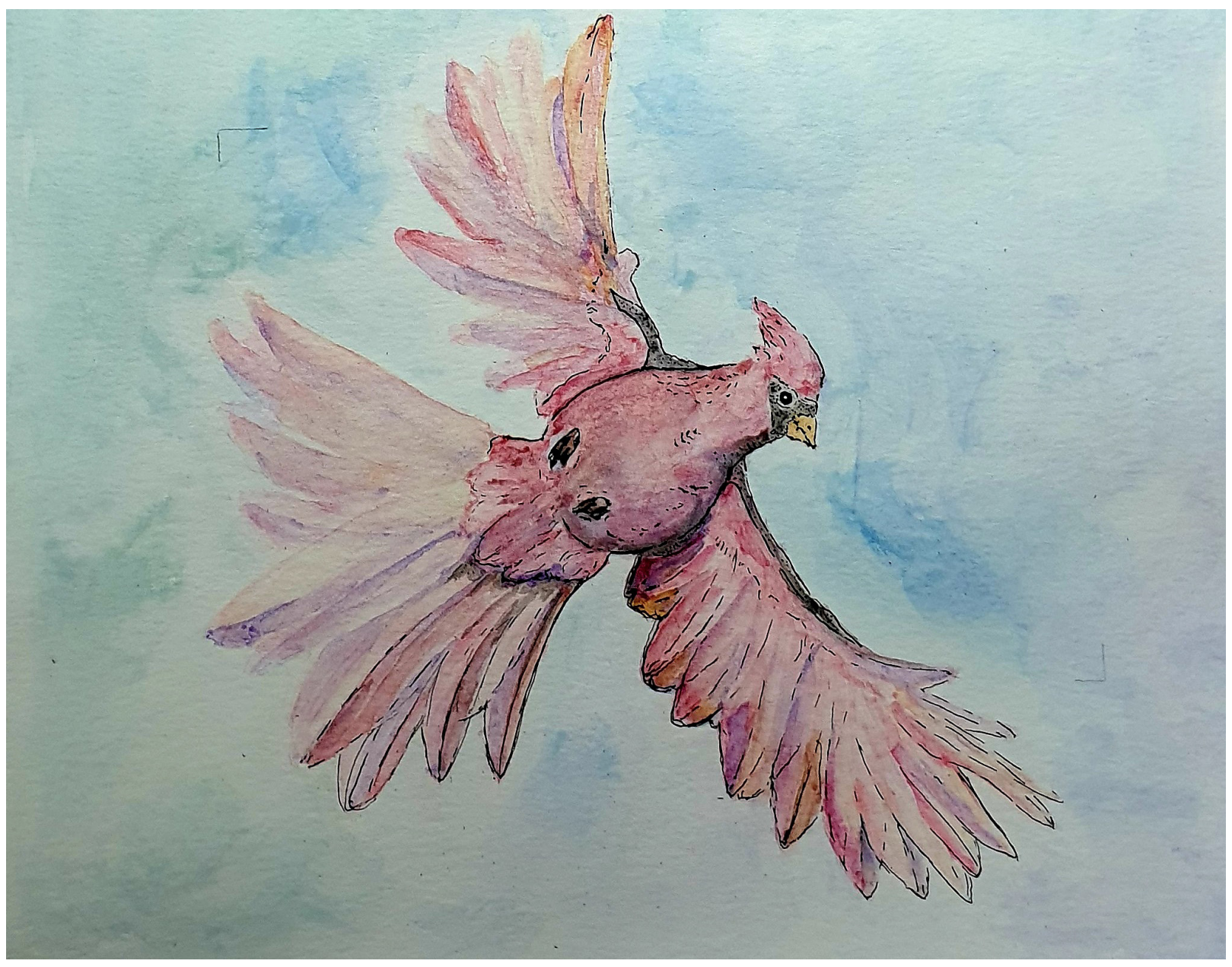

